\title{
0 trabalho de enfermagem em saúde mental a partir de proposições de acoplamentos tecnológicos
}

\section{Nursing care in mental health through proposals of technological couplings}

\begin{abstract}
Resumo
Este artigo apresenta uma experiência de trabalho com oficinas de fotografia dirigidas à equipe de enfermagem de uma unidade infantil e adolescente de um hospital psiquiátrico público em Porto Alegre. Esta proposta estava vinculada a um projeto maior, no qual todos os trabalhadores e jovens pacientes do hospital foram convidados a participar de oficinas de fotografia. O objetivo da proposta foi criar novas vias de exercícios de autoria a partir da tecnologia fotográfica e permitir a re-invenção de sentidos no coletivo. Para tanto, as oficinas foram divididas em quatro etapas: sensibilização para a condição simbólica/autoral da imagem; proposição de que os sujeitos fotografassem livremente; proposição de que os sujeitos fotografassem a partir da questão como você percebe este lugar? e relatos pós-fotográficos. As análises sobre estas quatro etapas indicaram que a fotografia é um objeto híbrido, capaz de ser tomado de diferentes formas, de acordo com o contexto no qual é produzida. A partir disto, foram possíveis discussões sobre as formas de visibilidade e resistência ao instituído que fazem parte do cotidiano de trabalho da enfermagem no hospital psiquiátrico.

Palavras-chave: Trabalho. Fotografia. Saúde mental. Enfermagem.

Abstract

This article presents an experience with photography workshops performed with the nursing team working at a child and adolescent clinic of a public psychiatric hospital in Porto Alegre, Brazil. This proposal was linked to a larger project, in which all workers and young patients of the hospital were invited to participate in photography workshops. The goal of the proposal was to create new ways to exercise authorship based on photographic technology and allow the reinvention of collective meanings. With this in mind, the workshops were divided into four stages: sensibilization to the symbolic/authorial condition of the image; a proposal for the subjects to photograph freely; a proposal for the subjects to photograph based on the question "how do you perceive this place?" and post-photographic reports by the subjects. The analyses of these four stages show that photography is a hybrid object, capable of taking different forms, according to the context in which it is produced. This enabled discussions about the forms of visibility and resistance to the institute that are part of the everyday nursing work in the psychiatric hospital.

Keywords: Labor. Photography. Mental health. Hursing.
\end{abstract}

MAURENTE, Vanessa. O trabalho de enfermagem em saúde mental a partir de proposições de acoplamentos tecnológicos. Informática na Educação: teoria \& prática, Porto Alegre, v. 13, n. 1 , p. $50-58$, jan./jun. 2010

\author{
Vanessa Maurente \\ Universidade Federal do Rio Grande do Sul
}

\section{Introdução}

A experiência discutida neste artigo foi uma das atividades do projeto de pesquisa e extensão Oficinando em Rede que, por sua vez, consiste em uma proposta de aproximação de um grupo de pesquisadores - professores, doutorandos, mestrandos, bolsistas de iniciação científica - da Universidade Federal do Rio Grande do Sul e técnicos do Centro Integrado de Atenção Psicossocial (CIAPS) do Hospital Psiquiátrico São Pedro (HPSP) / Porto Alegre. O projeto busca de um espaço de trabalho conjunto que possa ser algo além das duas instituições envolvidas: um campo de intervenções e produção de conhecimento que não esteja tão marcado pelos discursos acadêmicos ou hospitalares.

Neste contexto, foi realizado um trabalho de pesquisa e intervenção (MAURENTE, 2010), que tinha como uma de suas proposições a construção de vias de exercícios de autoria através de oficinas de fotografia digital no CIAPS. Tais oficinas foram dirigidas a todos os sujeitos que faziam parte da instituição: trabalhadores concursados, trabalhadores terceirizados, jovens usuários, estagiários, residentes e, inclusive, os próprios membros do projeto Oficinando vinculados à UFRGS. O presente artigo trata, então, das oficinas de fotografia realizadas junto à equipe de enfermagem do local, buscando discutir as práticas 
destes trabalhadores através de uma proposição articulada por tecnologias digitais.

O Hospital Psiquiátrico São Pedro faz parte da Rede Pública de Saúde do Estado do Rio Grande do Sul e é um local marcado por processos históricos diversos. Sua inauguração, há mais de um século, fez parte da série de acontecimentos que instituiu o modelo asilar de tratamento da loucura no Brasil, em uma época em que as irmãs de caridade assumiam o trabalho e a gestão de tais estruturas. Posteriormente, médicos passaram a ocupar os cargos de direção e autorizar as ações no local e a lógica hospitalar-psiquiátrica se torna hegemônica. A partir dos anos setenta se inicia uma abertura da instituição em função do movimento antimanicomial, que segue se produzindo em fluxos e refluxos até hoje.

Se a Saúde Mental no Brasil se tornou um campo heterogêneo de discursos, o Hospital Psiquiátrico São Pedro e o Centro Integrado de Atenção Psicossocial são locais onde a contradição se tornou efervescente e, por esta mesma razão, são espaços onde se criam condições de possibilidades de novas práticas. As oficinas de fotografia que serão abordadas neste artigo tinham como objetivo a problematização dos discursos em saúde mental em geral e das formas de trabalho e existência no CIAPS. Além disso, buscavam construir vias de expressão e autoria no espaço institucional. Sendo assim, um dos focos da intervenção consistiu em solicitar aos sujeitos que produzissem fotografias a partir da pergunta: como você percebe este lugar?

\section{No que consistem as oficinas de fotografia}

As chamadas oficinas terapêuticas não são uma novidade no campo da saúde mental, tendo nascido no contexto da reforma psiquiátrica. Entretanto, elas se apresentam como uma grande variedade de proposições, respondendo a objetivos distintos. De acordo com Guerra (2004), haveria quatro formas discursivas em torno das oficinas: o discurso do déficit, do inconsciente, da cidadania e da estética. $O$ discurso do déficit estaria relacionado a uma noção de que a oficina deve entreter os pacientes e teria como pressuposto a crença de que a ocupação é terapêutica por si só. No discurso do inconsciente, o sujeito seria tomado como a manifestação singular de uma estrutura clínica e a oficina serviria como operação de estabilização subjetiva. No discurso da cidadania, a ênfase estaria no respeito à diferença em prol da convivência e o objetivo da oficina seria a inserção sócio-política do paciente. Finalmente, no discurso estético, entenderia a loucura como uma manifestação singular de expressão que, através da oficina, poderia encontrar uma inscrição na cultura.

Nesta experiência as oficinas se colocaram como uma condição de possibilidade de produção de diferença através das tecnologias. Para tanto, buscamos nos descolar da pressuposição de que estas seriam ferramentas e centramos nossas formulações na noção de acoplamento tecnológico. De acordo com Maraschin e Axt (2005), o acoplamento tecnológico é um tipo especial de relação, ou seja, uma relação de constituição mútua na qual, dependendo da plasticidade das máquinas, elas também poderão realizar diferentes configurações internas. Tal relação sujeito-máquina não é fixa, mas se atualiza em diferentes formas, que podem ser consideradas resultantes da própria interação. Se a relação se estabelecesse de uma vez por todas, fixando um modo de existência sujeito-máquina único, não haveria um espaço para o imprevisível e, tampouco, para a tomada de uma posição de autoria nas produções advindas de tal relação por parte do sujeito em questão.

Nossa aposta era de que, a partir da construção de relações sujeito-tecnologia, novas formas de expressão e compartilhamento seriam possíveis em um espaço onde as posições de enunciação por vezes se mostravam rígidas. Além disso, as imagens produzidas foram consideradas expressões da singularidade e, ao mesmo tempo, vias para a criação de novos sentidos no campo da saúde mental, seja pela problematização das práticas manicomiais, seja pelo compartilhamento de modos de existência. Em função disto, elas tiveram um delineamento particular, construído com base em pesquisas anteriores com fotografia (TITTONI, 2004, MAURENTE; TITTONI, 2007) e no projeto Oficinando em Rede (SCISLESKI, 2006, DIEHL, 2007, VIANNA, 2008, CAPELA et al., 2008).

Este delineamento pode ser descrito por quatro etapas principais. A primeira delas consistia na problematização da imagem e sensibilização para a possibilidade de autoria 
do fotógrafo. Eram levados livros de fotografia (AVEDON, 2003, CUNNINGHAM apud LORENZ, 1996, MUNIZ, 2007, OMAR, 1997) e revistas com imagens, a respeito das quais eram feitas perguntas como: Quais Ihe chamam atenção?, Quais Ihe agradam?, Você acha que o fotógrafo dessa imagem teve alguma intenção?, Que intenção você acha que ele teve?, Como se poderia fotografar isso de outro jeito?, etc. Nesta mesma etapa os sujeitos recebiam uma moldura retangular de papel, chamada de máscara em educação em artes. Com esta máscara, os sujeitos deveriam selecionar uma parte das imagens recortadas das revistas e recortá-la novamente. Isto tinha como objetivo a sensibilização para o fato de que a fotografia é um recorte que envolve um processo ativo.

Em um segundo momento havia a experimentação da câmera digital através do exercício de fotografar livremente. Algumas instruções sobre a câmera eram passadas aos sujeitos, que posteriormente eram convidados a fotografar o que quisessem. Esta proposição foi baseada em experiências anteriores (TITTONI, 2004, MAURENTE, 2005, MAURENTE; TITTONI, 2007), nas quais observamos que muitos sujeitos, que nunca (ou quase nunca) haviam utilizado câmeras fotográficas, precisavam de um espaço de aproximação com a câmera. Sendo assim, muito pouco adiantava colocarmos uma questão antes deste momento, pois a questão era ignorada, dada a necessidade anterior de criação de relações com a tecnologia.

Em um terceiro momento os sujeitos eram convidados a fotografarem a partir da questão: Como você percebe este local? Finalmente, no quarto momento, eles eram convidados a escoIher algumas das imagens para uma exposição e também podiam falar sobre a experiência de fotografar, assim como sobre como chegaram até àquelas imagens. Tivemos o cuidado de não pedir que os sujeitos explicassem a imagem, mas pudessem falar a partir dela se quisessem. Isto remete a um processo de transdução (SIMONDON, 2009), ou seja, de possibilidade de passar de um particular a outro particular, de uma experiência a outra, e não de explicar uma forma de expressão a partir de outra.

Cabe salientar, ainda que consideramos a fotografia um objeto híbrido capaz de deixar questões em aberto no campo da história, da ciência, da arte e da ética por quase dois séculos. Apostamos que isto se deve à dificuldade que geralmente se têm de atribuir uma identidade à fotografia, dado que muitas definições Ihe parecem plausíveis, mas nenhuma conclusiva. Recorrendo a noções semióticas - ícone, símbolo e índice - de Charles Peirce, Dubois (1994) situa três posições fundamentais em relação fotografia, afirmando que ela poderia ser considerada, ao mesmo tempo, um ícone - algo que mantém uma relação com o referente por semelhança -, um símbolo - algo que mantém uma relação com o referente por convenção - e um índice - algo que mantém uma relação de contigüidade física com o referente. Nossas experiências têm indicado que contemplar esta complexidade parece ser a forma mais interessante de se trabalhar com fotografia em pesquisa.

\section{A experiência com a equipe de enfermagem}

As oficinas com a equipe de enfermagem eram uma demanda da instituição em função de que poucas propostas realizadas no CIAPS eram dirigidas a estes trabalhadores. Ao mesmo tempo, a proposta do projeto era tentar envolver todos os sujeitos em exercícios de autoria e na possibilidade de problematização das práticas ali realizadas - através da indagação sobre o local. Os integrantes da equipe de enfermagem são os trabalhadores da instituição que passam mais tempo com pacientes. Além disso, muitos deles possuem empregos em outros locais também, o que tornou muito difícil a negociação de um horário para realizar a oficina em grupo. Ao todo, foram cinco profissionais da área que participaram: Lilica (auxiliar de enfermagem), Ever (auxiliar de enfermagem), Joãozinho (estagiário de enfermagem), Ju (auxiliar de enfermagem e Ariam (residente de enfermagem) ${ }^{1}$.

Quando a proposta começou, houve um certo desânimo da parte dos sujeitos, seja por estarem sempre muito ocupados, seja pela suposição de incapacidade de produzir imagens e falar sobre elas, verbalizada constantemente. Entretanto, em nenhum momento foi dito que eles teriam que falar sobre as fotos. Isto aparecia como um convite em um momento

1 Nomes fictícios criados pelos sujeitos. 
posterior, mas não era um pré-requisito e a ênfase era sempre no processo de fotografar tentando responder a uma pergunta e compartilhar as produções no coletivo.

$\mathrm{Na}$ ocasião, Ever era auxiliar de enfermagem há um ano e meio no CIAPS. A experiência da oficina com este sujeito nos chamou muito a atenção em relação ao potencial de problematização do fotográfico. Isto ocorreu principalmente durante a etapa de sensibilização para a imagem. Quando questionado sobre se uma foto é de quem aparece nela ou de quem a tira, ele responde:

De nenhum dos dois. A foto é de quem olha. Quem olha é que vai sentir alguma coisa. Em segundo lugar é de quem tira, pois quem tira vai expressar um sentimento. E quem aparece não é nada, é só alguém que fica ali, parado. ${ }^{2}$

No momento de fotografar, Ever é muito minucioso. Ele prepara as fotos com objetos do lugar, montando cenas. Em certo momento, Lilica tira da mesa as coisas que ele arrumou para fotografar, sem perceber o que está fazendo. Um dos meninos, que estava jogando com outros, diz: "isso é pra foto do Ever, tia Lili". Então ela deixa. Ever diz ter gostado muito da fotografia 1 , pois considera que conseguiu se expressar através dela.

$\mathrm{Na}$ fotografia 2 Ever solicitou a participação de uma pessoa em sua imagem. Ao ver sua produção, ele afirmou ter conseguido o resultado que havia planejado: mostrar o ponto de visão de uma criança, ou seja, olhar um adulto de baixo pra cima, com um nível em uma altura bem mais baixa. Sobre a fotografia 3 ele disse que queria mostrar os elementos que fazem parte da vida das crianças ali.

"O tênis, mostrando a vontade de ir pra rua; o urso de pelúcia, mostrando a possibilidade de brincar e o cigarro, mostrando a possibilidade das drogas", diz. Neste momento as crianças, que estavam agitadas, aproximaram-se para ver o que estávamos fazendo e ficaram olhando a foto. Um deles disse: "Meu tênis!! É o meu tênis aqui!".

$\mathrm{Na}$ fotografia 4, Ever diz ter querido mostrar a água e a questão da purificação, que as crianças vem ali para "se purificar do que passam fora".

2 Os depoimentos estão em itálico para diferenciar das citações.

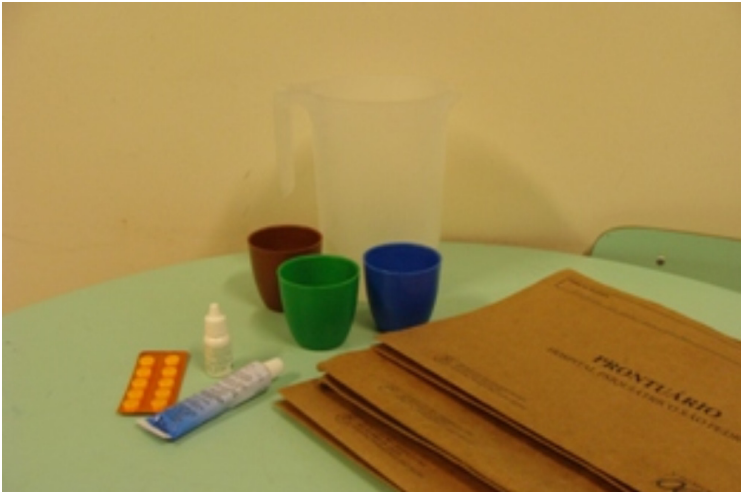

Fotografia 1 - Ever

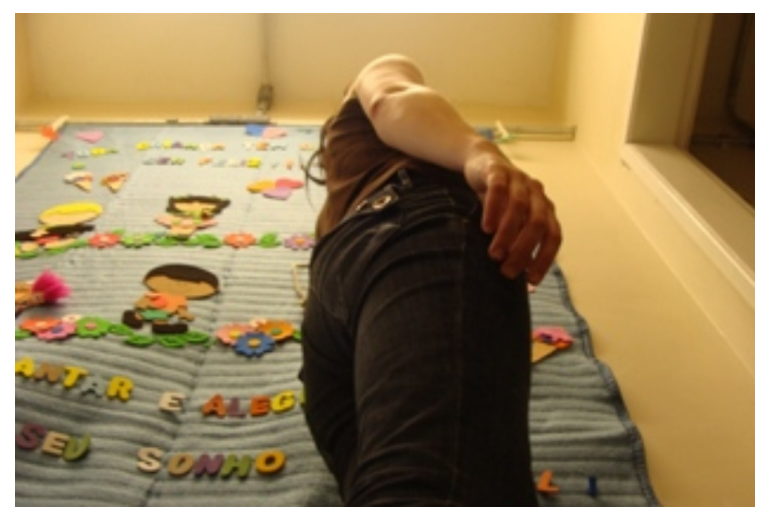

Fotografia 2 - Ever



Fotografia 3 - Ever



Fotografia 4 - Ever 


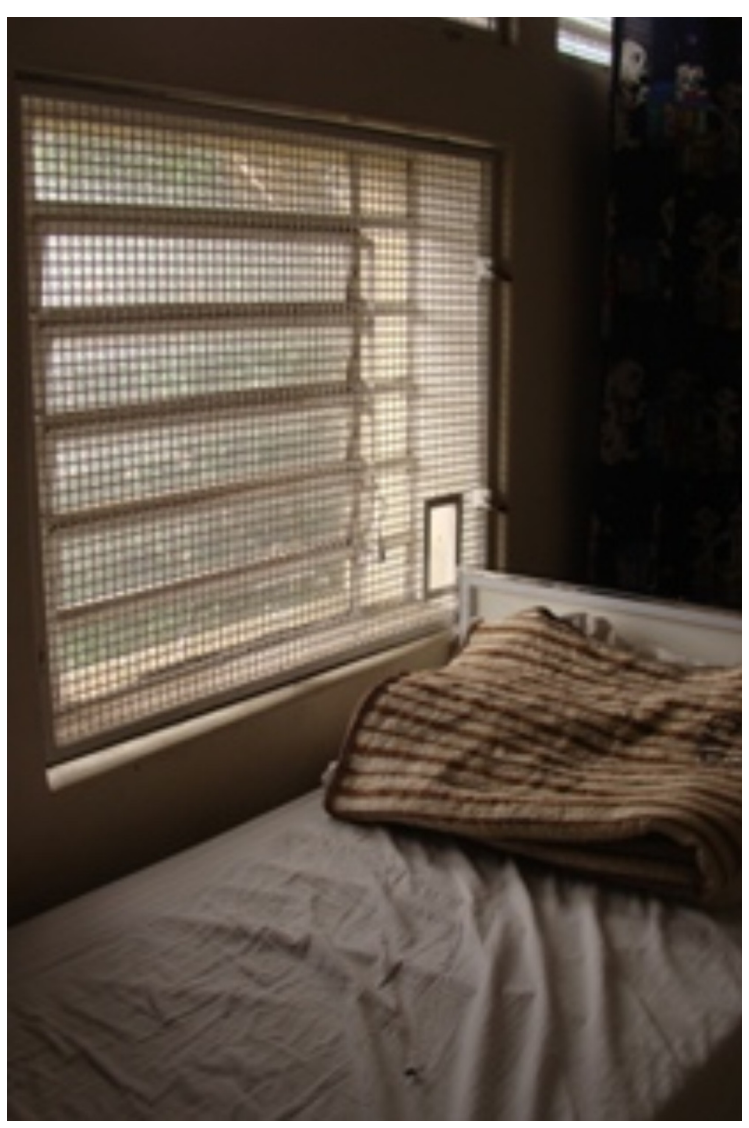

Fotografia 5 - Lilica

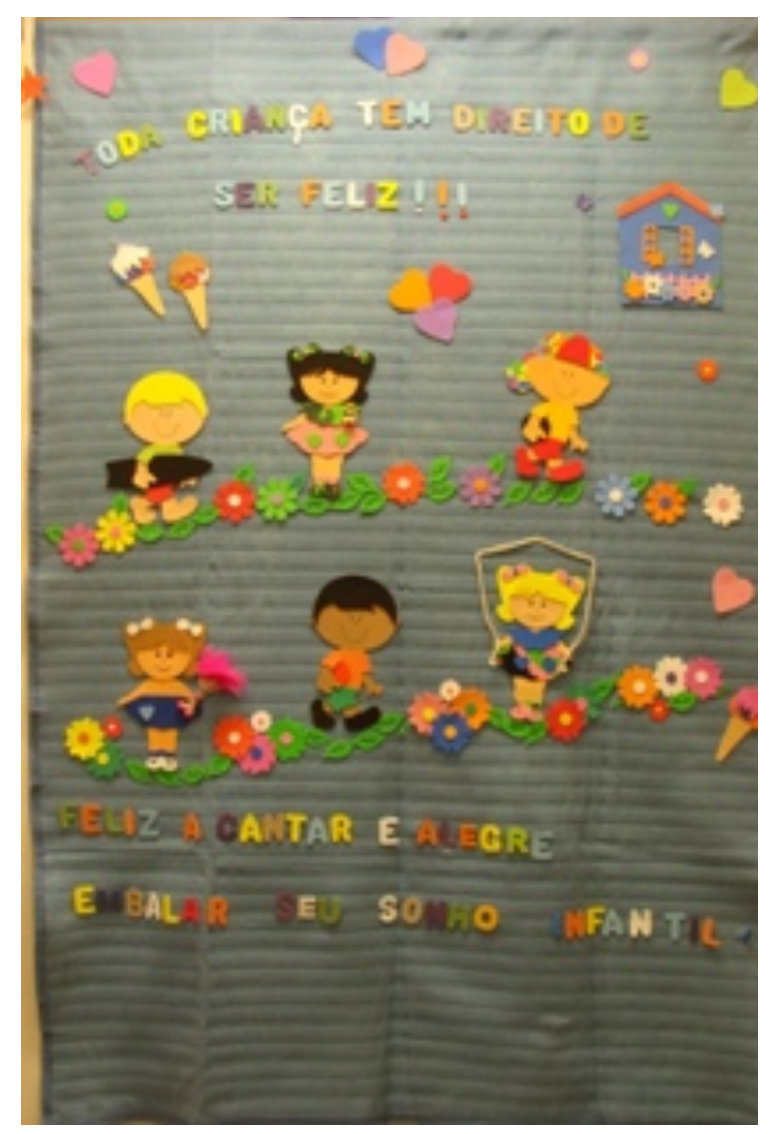

Fotografia 6 - Lilica

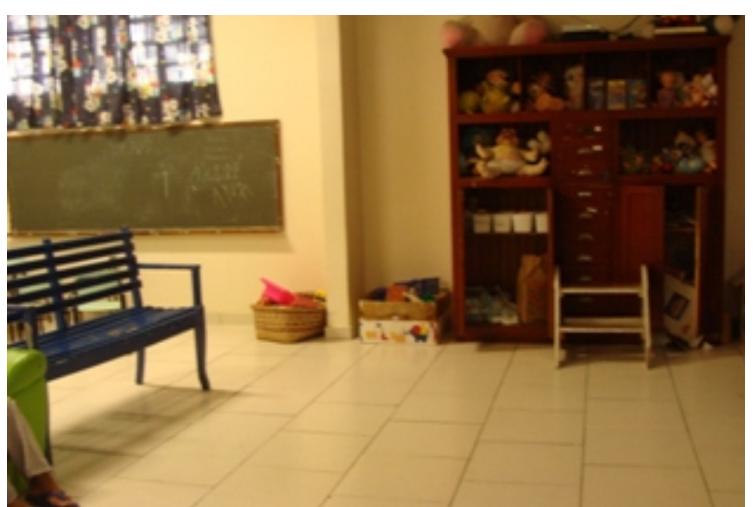

Fotografia $7-J u$

Lilica, também auxiliar de enfermagem, mudou de idéia em relação à participação na oficina três vezes. Ela afirmava ter interesse e vontade de fotografar, mas também dizia ter receios em relação à sua capacidade. Com a câmera na mão ela demorava muito para produzir imagens e olhava cada foto sua com muita atenção. Disse que gostou das fotografias 5 e 6, pois as duas mostraram o que ela queria.

Sobre a fotografia 5, ela repara nas grades e no lençol rasgado. Lilica considerou que as duas fotos mostravam o que ela pensava, pois uma mostrava "as dificuldades" (fotografia 5) e a outra mostrava "o que se busca" (fotografia 6). De acordo com Lilica, esta última (fotografia 6) seria o "ideal do CIAPS".

A terceira auxiliar de enfermagem que participou das oficinas produziu apenas uma imagem a partir da pergunta: da sala da internação infantil vazia, no momento em que as crianças saíram para o lanche (fotografia 7).

Esta fotografia pode ser considerada um efeito das restrições estabelecidas pelo Comitê de Ética do HPSP, de que nenhuma pessoa poderia aparecer nas imagens e, além disso, nenhum nome poderia ser divulgado. A medida considerada por eles como uma proteção aos jovens, dificultava em parte a produção fotográfica no local por alguns motivos. Entre eles, o mais elementar era o fato de que a unidade estava sempre cheia de pessoas e fotografar o espaço vazio exigia espera e paciência. Além disso, as fotografias sem pessoas expressam uma dinâmica um tanto distinta daquela experimentada no cotidiano do local.

O estagiário de enfermagem - Joãozinho e a residente de enfermagem - Ariam - também mudaram de idéia em relação à participação da oficina, afirmando que não tinham tempo. Entretanto, ambos acabaram participando. Eles solicitaram para fotografar no 
pátio e no museu do Hospital. Suas imagens trazem outros pontos de vista em relação às demais, pois foram produzidas em outro local e, juntamente com os relatos pós-fotográficos, apontavam para uma inseparabilidade entre Hospital Psiquiátrico São Pedro e Centro Integrado de Atenção Psicossocial. Isto nos levou a pensar nas contradições presentes no CIAPS, pois muitos trabalhadores consideram o serviço como distinto do Hospital, com funcionamento de Centro de Atenção Psicossocial (CAPS), enquanto outros o entendem como uma unidade de internação.

\section{Discussão}

A suposição de alguns dos sujeitos de que não seriam capazes de fotografar a forma como percebiam o local permitiu análises a respeito das formas de visibilidade relativas às práticas dos trabalhadores da enfermagem em saúde mental. Apesar de serem os profissionais que passam mais tempo imersos no serviço, estes sujeitos não se sentiam autorizados a falar do local a partir de uma posição de autoria. Esta desvalorização do próprio saber pode ser resultado de práticas institucionais rígidas, onde trajetórias singulares são desconsideradas e sufocadas pelo excesso de atividades diárias que, muitas vezes, acabam por se restringir à reprodução do saber legitimado no local.

Entretanto, percebemos que em alguns momentos estes trabalhadores rompiam com a norma institucional, em comportamentos que se afastavam do que estava prescrito por ela. Um exemplo disto é uma situação na qual Lilica sugere que um de nós abra a porta de saída do CIAPS com a chave e, deixando a porta aberta, volte até a sala das crianças para colocar a chave na gaveta. Além de permitir que a porta ficasse aberta, o local onde a chave fica guardada foi mencionado na frente dos jovens. Se nas unidades de pacientes crônicos do HPSP isto é algo freqüente, em função de que os sujeitos estão a tal ponto institucionalizados que já não podem pensar em sair sozinhos, no CIAPS os pacientes são, em sua maioria, jovens usuários de crack, que constantemente pensam em fuga. Por esta razão a atitude de Lilica foi surpreendente. Apesar disto, nada aconteceu, indicando que ela sabia o que estava fazendo, ainda que isto não estivesse completamente de acordo com as regras do local.

Em outro momento, os meninos estavam se agredindo fisicamente e chamavam Ever constantemente, ao que ele respondeu: "finjam que eu não existo". Considerando as regras de registro e controle do comportamento dos jovens no CIAPS isto também foi algo um tanto curioso. Em um primeiro era preocupante o fato de que os meninos poderiam se machucar consideravelmente. Mas, considerando a calma de Ever, é possível compreender que a situação era exatamente a mesma que se passa na rua, onde meninos brigam e conseguem resolver suas "diferenças" sozinhos. Esta confiança pareceu fundamental aos jovens, que logo pararam com as agressões.

Os auxiliares de enfermagem são sujeitos que estão em uma condição bastante peculiar na instituição. Por um lado eles recebem muitas "prescrições" sobre como trabalhar: que regras gerais seguir, como abordar cada paciente, que recursos físicos e químicos utilizar. Isto os coloca em uma posição de reprodução de um saber técnico especializado específico, que advém dos médicos, psiquiatras, psicólogos, pedagogos, enfermeiros. Entretanto, por outro lado, eles são os profissionais que estão mais tempo seguido junto com os jovens e por isto podem estar sensíveis às experiências singulares dos usuários do serviço. Além disso, há um espaço para a criação de formas de trabalhar particulares, capazes de escapar um pouco à rigidez das normas.

Existem formas de visibilidade e invisibilidade próprias ao trabalho destes sujeitos. Entender a posição peculiar que eles ocupam pode ser um caminho para a compreensão dos modos como eles se reconhecem nos jogos de verdade que definem as práticas no CIAPS. Neste sentido, a proposição de exercícios de autoria, onde a singularidade deve emergir, pode tornar relações visíveis e abrir vias de compartilhamento de experiências criativas. $\mathrm{Se}$, em um primeiro momento, o que apareceu foi uma recusa a fotografar, indicando uma suposição de incapacidade de tomar uma posição enunciativa sobre as práticas no serviço, em um segundo momento, a participação nas oficinas - que acabou ocorrendo - pôs em cena uma série de novos sentidos.

A etapa de sensibilização também permitiu que nós repensássemos a pergunta que 
estávamos colocando. Nosso objetivo era, principalmente, atentar para o fato de que a fotografia poderia ser uma produção de um sujeito, e não apenas uma reprodução da realidade. Porém, neste jogo, havíamos esquecido de acrescentar um elemento importante: a produção de sentidos/sensações/afecções de quem olha a imagem. Isto torna o receptor também um autor, como na escrita ou nas artes em geral.

Entretanto na fotografia a contemplação é um olhar que desdobra outro olhar que, por sua vez, produziu-se em sincronia com um referente. A imagem que se olha e partir da qual se pode produzir sentidos/sensações/afecções tem peculiaridades, pois é ícone, símbolo e índice ao mesmo tempo. A complexidade deste processo multiplica autores ao mesmo tempo em que permite que se os esqueça. Multiplica porque eles podem ser quem produz e quem olha. E permite que os esqueça porque ele pode esquecer estes dois, concentrando-se no que aparece - que para Ever "não é nada", mas em muitos outros contextos, como veremos, e para o Comitê de Ética do HPSP, é tudo.

Ever entende a intencionalidade em fotografia de uma forma interessante: Quando questionado sobre a condição do fotógrafo em relação às imagens ele diz:

Não. Nem sempre ele (o fotógrafo) consegue se expressar exatamente como quer e nem sempre ele quer expressar algo. Por exemplo, um fotógrafo de festas, aniversários, quer apenas registrar um momento. A pessoa que olhar a foto depois é que irá pensar ou sentir algo. Em outros momentos o fotógrafo pode ter uma intenção, pode querer expressar algo, como um sentimento. Mas também pode não conseguir.

De fato, uma imagem pode ter um caráter de registro, pode ser acidental. E ainda que um sujeito esteja intencionado, não há nenhuma garantia de que ele venha a considerar que alcançou seu objetivo ${ }^{3}$, pois o acoplamento tecnológico do qual resultam imagens fotográficas se produz numa esfera de imprevisibilidade. Ever experimentou isto no seu processo de fotografar, pois sempre situava as imagens em relação às quais estava satis-

3 Cabe salientar que compreendemos objetivo de uma forma ampla, onde poderia estar inclusa a experimentação tecno-visual como um fim estético em si. Neste sentido objetivo se aproxima de intenção e não de planejamento imagético. feito ou não. Apesar disto, ele demonstrava a consciência de que um sujeito que visse a sua foto poderia não compartilhar das sensações/ significados que ele quis expressar.

Estas produções reforçam a idéia de que os exercícios de autoria em fotografia não estão dados a priori. Eles dependem de relações entre sujeitos, tecnologias e regimes de verdade. Quando se trata de uma pesquisaintervenção, na qual se quer produzir ações e conhecimento através da fotografia, dependendo dos interesses que se têm, será necessário criar vias para o exercício de autoria.

Esta experiência se estruturou a partir do entendimento de que as condições de produções legitimadas estavam, em geral, restritas a poucas pessoas no CIAPS. Neste sentido, os exercícios de autoria poderiam fazer emergir trajetórias singulares a respeito das práticas no cuidado do sofrimento psíquico, marcando uma diferença nesta rede de sentidos que se apresentava de forma tão rígida. A estratégia utilizada para produzir relações entre sujeitos e tecnologia fotográfica, incluindo a possibilidade de exercício de autoria, foi a etapa de sensibilização. Entretanto, muitas outras estratégias podem - e devem - ser formuladas a partir da singularidade de cada contexto no qual se trabalha.

Em relação à fotografia como estratégia, observamos momentos em que cada uma das três posições epistemológicas - ícone, índice e símbolo - fez-se mais evidente. Ao mesmo tempo, estivemos atentos ao ato de produção fotográfica e às repercussões da fotografia já concebida, ou seja, ao potencial préindividual da imagem individuada nos campos discursivos nos quais ela circula. Por isso, as releituras verbais sobre as fotografias, realizadas pelos sujeitos que as produziam, pelo coletivo do CIAPS e em tantas outras redes de sentidos - exposições, congressos, grupo de pesquisa - foram muito importantes. Elas não foram tratadas como uma explicação da foto, mas sim como uma re-individuação a partir do encontro entre imagem e sujeitos/ coletivos.

A situação na qual Ever está "montando" sua foto em cima da mesa, com prontuários e caixas de medicamentos, Lilica recolhe o material para guardá-lo e um dos meninos diz para ela não mexer, pois "a foto é do Tio Ever" permite análises interessantes. Pois a criação de cenas para fotografias com objetos nos re- 
corda o estatuto ficcional destas imagens. No caso, Ever estava criando uma versão do próprio ambiente de trabalho, a fim de expressar a forma singular como percebe o local. Ele faz o mesmo em outras fotos (fotografias 2 e 3 ).

Ever explora as possibilidades fotográficas para produzir imagens e não registrar o cotidiano, como pode parecer ao discurso que compreende a fotografia apenas como ícone. Isto é compreensível se lembrarmos o que este mesmo sujeito fala sobre o referente em outro momento: "[...] quem aparece (na foto) não é nada. Só fica ali, parado." É interessante também pensar que o menino que avisou Lilica sobre a foto de Ever também percebeu isso, mesmo que ninguém tenha lhe dito nada.

Além de tomar a fotografia em sua complexidade epistemológica, buscamos compreendê-la como um objeto fisicamente individuado que mantém um potencial pré-individual nos campos discursivos nos quais ele circula e, por esta razão, está sujeito a defasar-se de si mesmo e tornar-se outra coisa a partir de campos metaestáveis. Isto significa que em diferentes regimes de verdade a fotografia será tomada de formas distintas. Em um campo de lutas, como o CIAPS, onde se tensionam diferentes formações discursivas sobre saúde mental, a fotografia poderá ser, a um mesmo tempo, tomada de muitas maneiras. Os exemplos trazidos anteriormente apontam para esta direção. Além disso, as experiências singulares dos sujeitos permitirão novos encontros com as imagens. Quando Lilica e os meninos da internação infantil olham uma imagem produzida por Ever (fotografia 3) um deles diz: "Meu tênis!".

De qualquer forma, esse campo de contradições nos diz que existem condições de possibilidade para novas práticas. Mostra-se necessária uma ética inventiva no campo da saúde mental, que possa dar seguimento às grandes transformações já conquistadas pela luta antimanicomial. É preciso criar novas portas de saída, espiar pelas frestas e, mais do que isso, mostrar o que se vê. A discussão sobre saúde mental precisa ser cada vez mais pública, para além dos meios acadêmicos, e para isso são necessárias muitas vias de informação e compartilhamento de experiências.

\section{Referências}

AVEDON, Richard. Portraits. New York: ABRAMS, 2003. Exibition at The Metropolitan Museum of Art, 26 sept. 2002/05 jan. 2003, New York, USA.

CAPELA, Nithiane; MARASCHIn, Cleci; MAURENTE, Vanessa S.; RICKES, Simone M.; DIEHL, Rafael. Tecnologias Digitais e Jovens Usuários de Serviço de Saúde Mental. Informática na Educação: teoria e prática, Porto Alegre, v. 11, n. 1, p. 79-90, 2008.

DIEHL, Rafael. Do Mapa à Fotografia: planografias de um espaço louco. 2007. Dissertação (Mestrado) Programa de Pós-graduação em Psicologia Social e Institucional, Universidade Federal do Rio Grande do Sul, 2007, Porto Alegre, BR-RS.

DUBOIS, Philippe. O Ato Fotográfico e Outros Ensaios. Campinas: Papirus, 1994.

GUERRA, Andréa M.C. Oficinas em Saúde Mental: percurso de uma história, fundamentos de uma prática. In: COSTA, Clarice M.; FIGUEIREDO, Ana C. (Org.) Oficinas Terapêuticas em Saúde Mental: sujeito, produção e cidadania. Rio de Janeiro: Contracapa, 2004. P. 23-58.

LORENZ, Richard. Imogen Cunningham: Flora. [S.I.]: Bulfinch, 1996.

MARASCHIN, Cleci; AXT, Margarete. Acoplamento Tecnológico e Cognição. In: VIGNERON, Jacques; OLIVEIRA Vera. Sala de Aula e Tecnologias. São Bernardo do Campo, Ed. da UMESP, 2005. P. 39-51. 
MAURENTE, Vanessa. Imagens do Hospício Vazio: fotografia, pesquisa e intervenção. 2010. Tese (Doutorado) - Programa de Pós-graduação em Informática na Educação, Universidade Federal do Rio Grande do Sul, 2010, Porto Alegre, BR-RS.

MAURENTE, Vanessa; MARASCHIN, Cleci; BIAZUS, Maria C.V. Modulações de Acoplamento Tecnológico Como Estratégia de Pesquisa e Intervenção. Educação e Realidade, Porto Alegre, v. 34, n. 1, p. 103-121, jan./abr. 2009.

MAURENTE, Vanessa; TITTONI, Jaqueline. Imagens em Pesquisa: a fotocomposição e outros caminhos possíveis. Psicologia e Sociedade: revista da Associação Brasileira de Psicologia Social, Porto Alegre, v. 19, n. 3, p. 33-38, 2007.

MUNIZ, Vik. Reflex: Vik Muniz de A a Z. São Paulo: Cosac \& Naify, 2007.

OMAR, Arthur. Antropologia da Face Gloriosa. São Paulo: Cosac \& Naify, 1997.

SCISLESKI, Andrea. Entre se Quiser Saia se Puder: os percursos dos jovens pelas redes sociais e a internação psiquiátrica. 2006. Dissertação (Mestrado) - Programa de Pós-Graduação em Psicologia Social e Institucional, Universidade Federal do Rio Grande do Sul, 2006, Porto Alegre, BR-RS.

SIMONDON, Gilbert. La Individuación. Buenos Aires: La Cebra, 2009.

TITTONI, Jaqueline. Saúde Mental, Trabalho e Outras Reflexões Sobre Economia Solidária. In: MERLO, Álvaro (Org.). Saúde e Trabalho no Rio Grande do Sul: realidade, pesquisa e intervenção. 1. ed. Porto Alegre. Ed. da UFRGS, 2004. V. 1, p. 65-93.

VIANNA, Tatiane R. Oficinas e Narrativas em Saúde Mental. 2008. Dissertação (Mestrado) - Programa de Pós-Graduação em Psicologia Social e Institucional, Universidade Federal do Rio Grande do Sul, 2008, Porto Alegre, BR-RS.

WADI, Yonissa. Palácio Para Guardar Doidos: uma história das lutas pela construção do hospital de alienados e da psiquiatria no Rio Grande do Sul. Porto Alegre: Ed. da UFRGS, 2002.

Recebido em junho de 2010.

Aprovado para publicação em agosto de 2010 .

\section{Vanessa Maurente}

Doutora em Informática na Educação. Universidade Federal do Rio Grande do Sul (UFRGS). Porto Alegre - RS/Brasil.

Email: vanessamaurente@yahoo.com.br. 